\title{
Erratum: Accurate and simple analytic representation of the electron-gas correlation energy \\ [Phys. Rev. B 45, 13244 (1992)]
}

John P. Perdew and Yue Wang

(Q) (Received 4 January 2018; published 14 August 2018)

DOI: 10.1103/PhysRevB.98.079904

Equation (B3) has a transcription error. In this equation, $\tan ^{-1}(u)$ should be replaced by $\tan ^{-1}(1 / u)$. This correction does not affect the rest of the paper. A detailed derivation is presented in Appendix A of Ref. [1].

[1] P. Bhattarai, A. Patra, C. Shahi, and J. P. Perdew, Phys. Rev. B 97, 195128 (2018). 